\title{
Matizes da cordialidade: a correspondência de escritores e inflexões dos debates no modernismo brasileiro
}

\author{
Silvana Moreli Vicente Dias*
}

\begin{abstract}
Resumo: Este artigo tem como objetivo discutir a possibilidade de se lerem as cartas inéditas trocadas entre os escritores Gilberto Freyre e Manuel Bandeira tomando por base o conceito de "cordialidade", tal como formulado pelo sociólogo em seu livro Sobrados e mucambos (1936). Cordialidade e epistolografia parecem articular-se na medida em que reforçam a aproximação entre elementos contrastantes, por meio de uma linguagem informal, relacional e ligada à vida cotidiana, a qual, por sua vez, se torna uma indiscutível pauta modernista, sobretudo a partir do final da década de 1920. Desse modo, faremos considerações sobre uma espécie de predisposição cordial no modernismo brasileiro a partir de informações sub-reptícias presentes na própria forma epistolográfica e em outros documentos dos arquivos dos escritores.
\end{abstract}

Palavras-chave: Gilberto Freyre. Manuel Bandeira. Correspondências. Modernismo. Epistolografia.

\section{De esguelha em papéis de arquivo}

A correspondência inédita trocada entre os escritores Gilberto Freyre e Manuel Bandeira abre possibilidades diversas de reflexão. Nela, é possível encontrar desde o diálogo intertextual com escritos publicados de Freyre ou de Bandeira, rastros da gênese de obras fundamentais como Casa-grande \& senzala (de Freyre, 1933) ou Libertinagem (de Bandeira, 1930), até a abertura para se compreenderem redes de relações mais amplas, com aspectos novos da movimentação de intelectuais, literatos e artistas no contexto do Brasil da primeira metade do século XX. Na trilha de Marcos Antônio de Moraes em sua reflexão sobre epistolografia, ao conceito de "sistema

\footnotetext{
* Silvana Moreli Vicente Dias realiza seu segundo pós-doutorado no Instituto de Estudos Brasileiros da Universidade de São Paulo (IEB-USP), com Bolsa Prêmio CAPES de Tese. Este artigo foi escrito com base em pesquisa de doutorado cuja tese resultante, financiada pelo CNPq, foi defendida pelo Departamento de Teoria Literária e Literatura Comparada, Faculdade de Filosofia, Letras e Ciências Humanas - Universidade de São Paulo. A autora, inclusive, aproveita para agradecer à Fundação Gilberto Freyre a disponibilização de seus arquivos para a pesquisa, bem como à socióloga Michele Asmar Fanini a gentileza em discutir este trabalho e oferecer sugestões. Contato: silmoreli@usp.br
} 
literário" elaborado por Antonio Candido ${ }^{1}$ devem-se somar as falas encobertas das cartas, enriquecendo sobremaneira - por situar-se além dos elementos "autor, público leitor e tradição" - a compreensão da vida literária nacional. Procuraremos justamente, no traçado de textos encobertos pelo tempo, situar uma espécie de dinâmica específica para além da imagem de autores públicos que o tempo tem ajudado a moldar.

O pano de fundo do diálogo entre Gilberto Freyre e Manuel Bandeira implicou o trânsito de tarefas, favores, apreciações críticas e impressões "amigas", num contexto em que a dinamização da sociedade, com os primeiros surtos de industrialização, com a expansão do trabalho assalariado e do mercado, com a tentativa de modernização da administração pública e com a expansão dos meios de comunicação, influenciou enormemente o trabalho intelectual e artístico, que caminhava para conquistar sua autonomia. Nesse contexto, Bandeira assumiu o papel de articulador de dois universos, do Norte e do Sul, simbolizados, de um lado, por Gilberto Freyre e, de outro, por Mário de Andrade (1893-1945) - com quem já tinha iniciado uma frutífera troca epistolar, a qual se avolumaria nos anos seguintes e se encerraria apenas com a morte precoce do paulista.

Focando especialmente a década de 1920 e considerando-se o fato de que estamos na trilha de dois autores fundamentais para as transformações culturais e estéticas então em curso - o recifense Gilberto Freyre, à época, residia no Recife e Manuel Bandeira, também recifense, já estava estabelecido no Rio de Janeiro desde o início da adolescência -, é elemento significativo o fato de que a carta de abertura da Correspondência seja dedicada ao Livro do Nordeste, "Edição comemorativa do primeiro centenário do Diário de Pernambuco" (FREYRE et al., 1979), de 1925, organizado por Gilberto Freyre e com a colaboração de diversos escritores e intelectuais de reconhecida envergadura intelectual. Para Bandeira, participar do Livro do Nordeste significaria não somente o contato com uma rede de sociabilidade pernambucana, mas também o encontro de sua poesia com a experiência, a memória, o cotidiano, a infância, temas ainda preteridos nos anos do chamado modernismo heroico do início da década de 1920, que, apesar de apresentar eventuais laivos prémodernistas, ansiava uma atualização vanguardista. O impacto do encontro com Freyre e seus colegas é sugerido pelas linhas da carta de 12 de dezembro de 1925:

[...] Que prazer tive de olhar os desenhos do Bandeira! Quem é esse estupendo xará? É Manuel também? Ele está juntando um tesouro! [...] O artigo do Cardozo... Aquele sacana me deixou o coração numa podreira. Que sujeito penetrante vai entrando por a gente adentro me conte alguma coisa dele. $[\ldots]^{\prime \prime}{ }^{2}$

\footnotetext{
1 Antonio Candido, ao explicar a orientação crítica que norteia a sua Formação da Literatura Brasileira, distingue "manifestações literárias" de "literatura", sendo este conceito tomado como "um sistema de obras ligadas por denominadores comuns, que permitem reconhecer as notas dominantes duma fase. [...] Entre eles se distinguem: a existência de um conjunto de produtores literários, mais ou menos conscientes do seu papel; um conjunto de receptores, formando os diferentes tipos de público, sem os quais a obra não vive; um mecanismo transmissor (de modo geral, uma linguagem, traduzida em estilos), que liga uns a outros" (CANDIDO, 1993, p.23).

2 Referida carta é apresentada na edição do conjunto epistolar, proposta em minha tese de doutorado (VICENTE, 2008), pela seguinte nota: "Classificação original (FGF): doc 1. Carta.
} 
A intenção explícita de Freyre na edição do Livro do Nordeste era reunir um pensamento de vanguarda, articulando visões diversas de Nordeste, com artigos que vão de rendados a comida, de vida social a política, bem como dar a ideia de uma espécie de estética alternativa da vida moderna centrada na província, por meio de desenhos do jovem Manoel Bandeira (1900-1964) ou dos versos líricos do escritor Manuel Bandeira, que contribuiu com o seu conhecido "Evocação do Recife", escrito a pedido de Freyre. Os elogios nessa carta inaugural ao também jovem Joaquim Cardozo (1897-1978) são mais que merecidos: seu apurado senso crítico está, de fato, aliado a uma grande sensibilidade. Observe-se como a pontuação (ou sua ausência) na carta de Bandeira surpreende ao dar ligeireza e maior plasticidade à escrita epistolar: "Que sujeito penetrante vai entrando por a gente adentro me conte alguma coisa dele". É como se o poeta, em carta, encontrasse um modo de expressar o sentimento de arrebatamento ("Aquele sacana me deixou o coração numa podreira") causado por Cardozo, que - entre outras tantas linhas que antecipam o que a crítica especializada, décadas após, viria a estabelecer como eixos interpretativos da poesia de Bandeira escreve:

\begin{abstract}
Pobre menino doente a olhar através da vidraça os balõezinhos que sobem, os pequenos vendedores de carvão, as carroças de leite, os sapos e os vaga-lumes, a observar na rua pequenos detalhes desprezados, quase impercebidos como qualquer garoto se volta para apanhar um objeto insignificante abandonado no chão; esse olhar amoroso para as cousas esquecidas, esse interesse pela ingenuidade dos brinquedos se veem em "Noite morta", "Na rua do sabão", "Meninos carvoeiros", "Balõezinhos". [...] Ah! esta volúpia amarga de viver, esta "tristeza dos que perderam o gosto de viver" e que em tudo e acima de tudo adoram a vida! (CARDOZO in FREYRE et al., 1979, p.125)
\end{abstract}

A epistolografia como forma literária passava por transformações, por exemplo, deixando a retórica que era característica dos códigos no século XIX por uma linguagem rápida e de aparente superficialidade - digo aparente, sem excluir, por certo, seu grau de complexidade, que se torna cada vez mais sutil. Vê-se, por essa carta de 12 de dezembro de 1925, bastante informal para os padrões da época, como os escritores vão se aproximando, trocando ideias, encomendando trabalhos um ao outro. A sutileza da suposta autonomia em contexto brasileiro dá-se justamente porque a arte no país, no geral e passando ao largo das polêmicas individuais, se forma e se afirma negando-a, na medida em que valoriza a comunicação, a identidade e o artesanato a partir de uma linguagem orgânica que apenas se amplia com a técnica moderna, sem questionar, de forma consequente, a narratividade, a temporalidade e o valor da unidade dos objetos artísticos. A rapidez e a fragmentação do mundo novo deixam marcas na estrutura dos gêneros - com os caminhos tomados pela crônica no Brasil, isso fica bem claro e, em particular, exerce força também na epistolografia -, assim como tornam cada vez mais complexas as redes de convivência que se formam.

Manuscrito autógrafo com caneta tinteiro preta. Datação original: 'Rio, 12 dezembro 1925'. Papel amarelado, de gramatura média. Duas folhas, duas páginas manuscritas. Dimensões: 27 $x 21,2 \mathrm{~cm}$. Documento em boas condições." 
Ao contrário das vanguardas europeias, em que a tentativa de devolver a arte à práxis é bem radical, como defende Peter Bürger (1993), aqui, no Brasil, arte e práxis parecem articular-se em uma construção que alia o sentido e seu avesso, paradoxalmente. E amizade e trabalho artístico são duas coisas que se mesclam, muito generosamente, num ambiente cordial, tornando mais intrincada a condição de autonomia da arte em contexto nacional. Assim, a cordialidade parece ser uma marca fundamental da sociabilidade dessa geração de escritores e intelectuais, que deixam seu rastro nas próprias formas de composição da época, desde as mais simples, ligadas à vida comezinha, às mais complexas, produzidas para serem comercializadas.

No acervo pessoal de Gilberto Freyre, sob a guarda do Centro de Documentação da Fundação Gilberto Freyre, há vários documentos que remetem a uma imbricação entre técnica moderna e desejo de pertencimento. Gostaria de destacar especialmente uma imagem sem título ou determinação de autoria. O mundo da técnica, que se amplia e ajuda a diversificar os modos de produção e reprodução de imagem, é o elemento de fundo de uma fotomontagem que simboliza a articulação paradoxal entre os avanços da modernidade e o pendor localista - que, afinal, foi a aventura também de paulistas, simbolicamente representada, por exemplo, pelas viagens (reais e literárias) de redescoberta do Brasil "interior". ${ }^{3}$ Aqui utilizo a expressão "elemento coadjuvante" para ressaltar o quanto a linguagem técnica inspira e influencia os novos artistas, que procuram explorá-la como melhor lhes convém. Este ponto é anterior à questão da presença mais patente dos cinematógrafos e fonógrafos de que fala Flora Süssekind (1987), quando a técnica se revela um elemento fundamental de representação literária, com diferentes níveis de problematização, e acaba por influenciar, segundo a argumentação da autora, a nova linguagem modernista, como em Serafim Ponte Grande, de Oswald de Andrade. Ou ainda, vale dizer, o que pretendo argumentar, ao me deter no conceito de "cordialidade", é algo semelhante ao que se dá no caminho inverso da técnica, como se um complementasse em alguma medida o outro e ambos traduzissem, com variedade de grau, o processo tortuoso de modernização nos campos artístico e intelectual que se acelera no país dos anos 1920 e 1930 .

A fotomontagem em questão, localizada na Fundação Gilberto Freyre, ao que tudo indica preparada artesanalmente também pelo processo de fotopintura, não é datada nem possui autoria declarada. Com as dimensões de $23,9 \mathrm{~cm}$ de largura por $17,9 \mathrm{~cm}$ de altura, a imagem traz os seguintes personagens centrais na história do Modernismo brasileiro, assim identificados pela própria Fundação Gilberto Freyre: Luís Jardim (1901-1987), Manuel Bandeira, Tarsila do Amaral (1886-1973), Heitor VillaLobos (1887-1959), José Lins do Rego (1901-1957), Gilberto Freyre e Oswald de Andrade (1890-1954). Ainda que se possa divergir dessa identificação, visto que a imagem obviamente não se pauta pela perfeita literalidade, é fato que tais nomes figuram no próprio documento de arquivo.

3 O tema da viagem, caro para o movimento modernista no país, culminou, por exemplo, na "monumentalização" do barroco mineiro. Nesse sentido, é famosa a viagem empreendida para o interior de Minas Gerais, em 1924, pela caravana paulista, formada pelos "mecenas" René Thiollier e Olívia Guedes Penteado acompanhados de Mário de Andrade, Tarsila do Amaral, Oswald de Andrade, Blaise Cendrars e Gofredo da Silva Teles, com o intuito declarado de "redescobrir" o Brasil. 


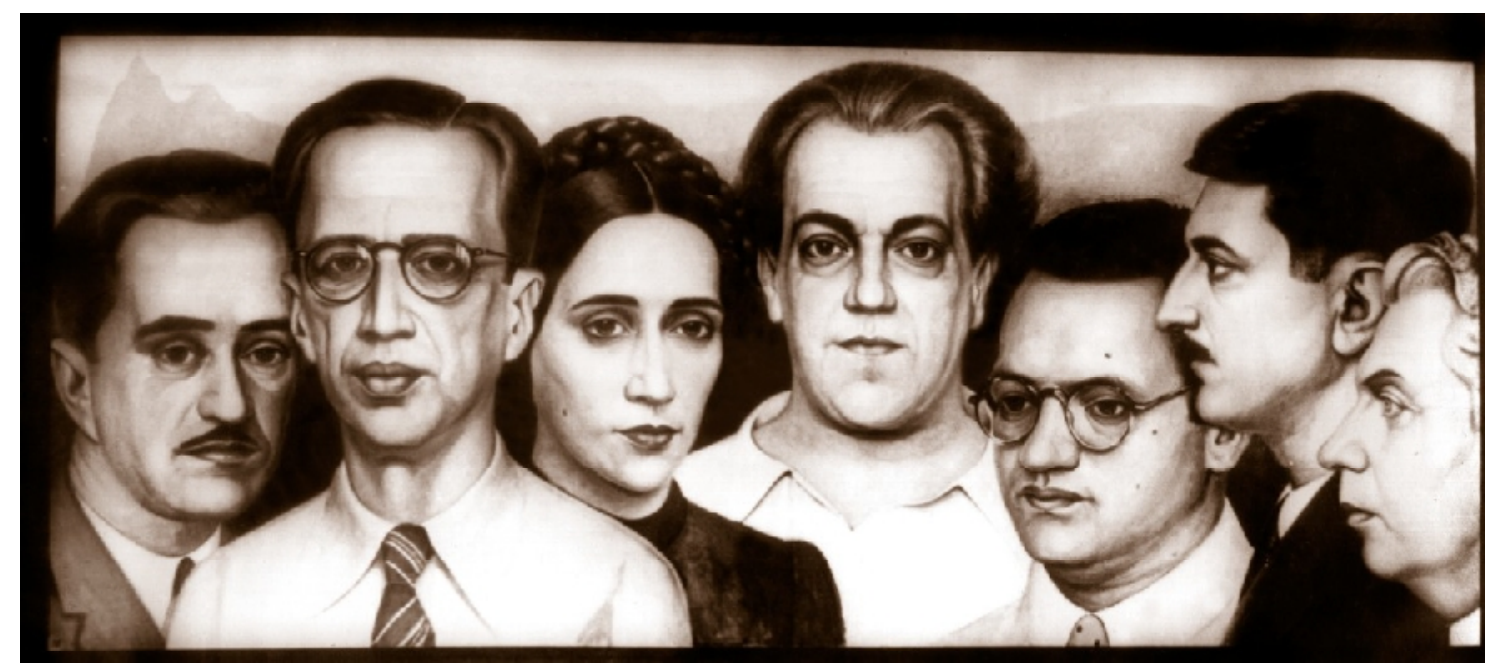

Figura 1. Fotomontagem, da esquerda para direita (provável identificação): Luís Jardim, Manuel Bandeira, Tarsila do Amaral, Heitor Villa-Lobos, José Lins do Rego, Gilberto Freyre e Oswald de Andrade. ${ }^{4}$

Fonte: Centro de Documentação da FGF. Notas: Sem datação. Autoria desconhecida.

Dimensões: $17,9 \times 23,9 \mathrm{~cm}$.

É interessante notar também que, a despeito da posição lado a lado ou quase justaposição de obras ensaísticas, literárias e artísticas paradigmáticas que formariam uma espécie de complexo "sintagma do modernismo brasileiro", há um notável desencontro de olhares. Metonimicamente, é como se os olhos representassem projetos artísticos e literários fundamentalmente autorais, singulares (sobretudo os de Luís Jardim, Tarsila do Amaral e José Lins do Rego), dentre os quais o de Manuel Bandeira e o de Villa-Lobos sintetizariam a capacidade de estabelecer um contato vivo, franco e direto com seu público. Por sua vez, Freyre e Oswald encontram-se perfilados, como se fitassem um mesmo ponto longínquo ou buscassem costurar visões artísticas e intelectuais distintas sob a rubrica de um "modernismo brasileiro", de feição singular e multiforme - é interessante destacar que, além da admiração mútua, afirmada após os anos combativos do modernismo, tanto Freyre quanto Oswald tinham, em linhas gerais, uma visão estética simultaneamente agregadora, heterogênea e não hierárquica, como notamos pelos conceitos de "amálgama de antagonismos" (Freyre) $)^{5}$ e de "antropofagia" (Oswald de Andrade). ${ }^{6}$

\footnotetext{
${ }^{4}$ Referida imagem pode ser visualizada no caderno iconográfico de minha tese de doutorado. Cf. VICENTE, 2008, p.193.

${ }^{5}$ Sobre o "processo de equilíbrio de antagonismos", cf. conhecido parágrafo de Freyre, de Casagrande \& senzala: "Considerada de modo geral, a formação brasileira tem sido, na verdade, como já salientamos às primeiras páginas deste ensaio, um processo de equilíbrio de antagonismos. Antagonismos de economia e de cultura. A cultura europeia e a indígena. A europeia e a africana. A africana e a indígena. A economia agrária e a pastoral. A agrária e a mineira. O católico e o herege. O jesuíta e o fazendeiro. O bandeirante e o senhor de engenho. O paulista e o emboaba. O pernambucano e o mascate. $O$ grande proprietário e o pária. 0 bacharel e o analfabeto. Mas predominando sobre todos os antagonismos, o mais geral e o mais profundo: o senhor e o escravo." (FREYRE, 2003, p.116).
} 
O pintor e escritor pernambucano Luís Jardim e o escritor paraibano José Lins ficariam, por sua vez, ligados ao romance de análise social e à arte de expressão regional. Já o músico Villa-Lobos procurou realizar uma obra universal - como ele mesmo afirmava - que trabalhasse sobretudo com aspectos da música popular brasileira. Tarsila e Oswald, na década de 1920, formariam uma parceria que extrapolou o universo da intimidade e deixou marcas indeléveis na trajetória artística de ambos, abalizada pela elaboração de uma estética que lançava mão da simultaneidade e da montagem modernas articuladas à representação pretensamente ingênua de paisagens e de retratos brasileiros. Um corte que diferenciaria substancialmente os vários personagens do grupo - que souberam dosar, de forma criativa, ingredientes nacionais - poderia ser a profundidade do humor, do aspecto carnavalizante, que seria quase nulo em Jardim e intenso em certo Oswald. Gilberto Freyre, convergindo mais uma vez para Oswald de Andrade, também soube fazer uso de uma escrita desestabilizadora e inquietante, como o vemos em várias páginas de seu ensaio de interpretação do Brasil Casa-grande \& senzala, e dela fugiu quando parecia mais conveniente convencer a opinião pública, em meio a ataques e acusações de diletantismo e intuitivismo, de que era um intelectual que sabia utilizar a linguagem mais acadêmica e sabia fazer ciência, o que ocorre sobretudo após a década de 1930.

De qualquer modo, essa fotomontagem mostra bem que havia um círculo de sociabilidade que se queria reconhecido, um círculo se articulando com vários outros e que, aliás, não podemos afirmar se existiu ou se haveria, de fato, alguma relação profunda ou duradoura entre os referidos personagens. A imagem pode ter sido um presente dado a Gilberto Freyre, ou mesmo uma encomenda do próprio escritor, já que um ponto certo de contato com todos esses artistas é o sociólogo, que de fato os admirava e que - por que não? - queria ver-se incluído nos grupos artísticos e intelectuais do Rio e de São Paulo. Ou, ainda, talvez tenha vindo do próprio Bandeira, elemento central e de olhar fixo rumo ao observador virtualmente posicionado à frente da imagem. De qualquer modo, apesar dessa quase obsessão pelo pertencimento a um grupo socialmente reconhecido, para além de um mero distintivo geracional, é sabido que os agrupamentos se faziam e se desfaziam, eram ajuntamentos muito dinâmicos: veja-se, por exemplo, o destino melancólico do "grupo dos 5", formado por Tarsila do Amaral, Mário de Andrade, Oswald de Andrade, Menotti del Picchia e Anita Malfati. ${ }^{7,8}$

6 Oswald de Andrade procura solucionar o complexo local-cosmopolita de modo utópico, assimilando a linguagem vanguardista. Veja-se trecho do "Manifesto Antropófago", publicado na Revista de Antropofagia 1, em maio de 1928: "[...] Nunca fomos catequizados. Fizemos foi Carnaval. O índio vestido de Senador do Império. Fingindo de Pitt. Ou figurando nas operas de Alencar cheio de bons sentimentos portugueses. / Já tínhamos o comunismo. Já tínhamos a língua surrealista. A idade de ouro. / Catiti Catiti / Imara Notiá / Notiá Imara / Ipejú." (ANDRADE, 1995, p.144).

7 Segundo Sergio Miceli, "[...] o foco de tensões internas no grupo possuía um inequívoco componente étnico - os 'nacionais' Mário, Tarsila e Oswald versus os oriundi Anita e Menotti -, e não se pode descartá-lo da análise das obras e tomadas de posição de todos os envolvidos. Os percalços de Anita para conquistar a bolsa de estudos concedida pelo Patronato Artístico, as reações ambivalentes de Mário e o rechaço terminante de Oswald perante os escritos romanescos de Menotti, e as ciumeiras entre Tarsila e Anita são alguns dos episódios capazes de sinalizar os caminhos tortuosos desse embate de forças e capitais desiguais, instigados pelo acicate venenoso do desapreço étnico, misto de competição, embaraço e desconforto envolvendo esses parceiros com trunfos tão desiguais." (MICELI, 2003, p.115). 
No Brasil, a despeito de soluções bastante criativas, afirmação esta que se reporta especialmente à técnica modernista, como no caso do Oswald e da Tarsila antropofágicos, da Anita da primeira fase, do Mário de Macunaíma, do Freyre de Casagrande \& senzala e do Bandeira de Libertinagem, o pendor localista ou étnico, como um reflexo ao revés, foi um ponto permanente de debate - e, onde há debate, há grupos atuando - dentro do projeto de modernização artística no país, ao lado da preocupação com a adequação técnica. E, nesse sentido, a cordialidade engajada, com lastro na troca de amenidades e na lhaneza das relações interpessoais, imbuída ou não de valores duradouros, acabou sendo uma característica da convivência de certos grupos nesse período.

Ademais, na Literatura Brasileira pode-se perceber que a questão da necessidade de junção entre adequação técnica e tendência local, entre cosmopolitismo e provincianismo, entre modernidade e tradição, com grau variável de complexidade crítica e mediação, não foi exclusiva daquele período. Gerações e grupos que vieram depois continuaram a dialogar com os primeiros modernistas, por exemplo, com a proposta de se pensarem as especificidades e incoerências estéticas em um país marginal (cf. GULLAR, 1969). Para além de se notarem incompatibilidades insolúveis, por sua vez, Gilberto Freyre procurou observar os termos em relação, notando como a apropriação progressiva de um arcabouço liberal e ocidental poderia conter de perdas e ganhos estéticos, culturais, políticos e sociais, o que foi exemplarmente discutido em Sobrados e mucambos - cf. capítulo "O Ocidente e o Oriente". É em sentido simultaneamente crítico e relacional, portanto, que o autor procurou desenvolver termos como "cordialidade", como veremos a seguir. ${ }^{9}$

\section{2 . No rastro de crônicas mundanas}

O divagar do cronista paralelo a uma sensibilidade cordial constitui a tônica da Correspondência de Gilberto Freyre e Manuel Bandeira. A informalidade entre os

\footnotetext{
${ }^{8}$ Vale dizer que Heloísa Pontes, no livro Destinos mistos (1998), abordou a temática dos "grupos" de modo exemplar. A reconstrução da trajetória do grupo da revista Clima [cujos integrantes, dentre outros, foram Antonio Candido, Décio de Almeida Prado, Paulo Emílio Salles Gomes e Gilda de Mello Souza] deu-se modulando cortes complementares, tais como o geracional e o de gênero. Essas leituras originais, sobretudo no que diz respeito à presença feminina e a sua participação em esferas menos valorizadas da criação artística e intelectual, foram ainda retomadas em Intérpretes da metrópole (2010), da mesma autora. Inclusive, vale a pena citar uma apreciação da antropóloga sobre a revista Clima que demonstra o quão difícil é operaremse rupturas com visões hegemônicas e elitistas: "A postura política sustentada pelos editores de Clima durante o período de circulação da revista [...] não fora suficiente para que rompessem com a visão dominante entre as elites dirigentes sobre o universo social e cultural das camadas desprivilegiadas do país. Não é aleatório, portanto, que o primeiro movimento consistente de ruptura com essa visão tenha partido de um outro integrante da Faculdade de Filosofia, com quem até então se relacionavam de maneira distante: o jovem sociólogo Florestan Fernandes." (PONTES, 1998, p.138).

9 Parece-me esclarecedora, neste ponto, a seguinte afirmação de Jessé Souza: "Freyre é o mesmo pensador holista, que pensa a sociedade como um todo orgânico a partir de partes que se completam. Nesse tipo de concepção de sociedade, a hierarquia é o dado central e cada pessoa, grupo ou classe tem o 'seu lugar'. [...] sua atenção esteve sempre voltada para perceber formas de integração harmônica de contrários, interdependência e comunicação recíproca entre diferentes, sejam essas diferenças entre culturas, grupos, gêneros ou classes." (SOUZA, 2000, p.212).
} 
amigos e o burburinho acerca da vida alheia parecem diminuir consideravelmente a distância que há entre Rio de Janeiro e Recife: tudo se torna uma aldeia, palco de risadas nos dois lados do canal comunicativo. Os amigos se ajudam e se inspiram, a ponto de ficar difícil delimitar onde terminam os assuntos íntimos e banais e se iniciam os assuntos sérios e consequentes, como a preocupação com os destinos do país. 0 sentido "mundano", tomando de empréstimo o conceito usado por Edward Said para "denotar o mundo histórico real de cujas circunstâncias nenhum de nós jamais pode estar separado, nem mesmo em teoria" (SAID, 2007, p.71), fica absolutamente evidente neste conjunto, em que quase não se observa um embate teórico consistente ou uma discussão estética mais profunda, exemplos dos quais está plena - para mencionar apenas um conjunto epistolar efetivamente editado - a Correspondência Mário de Andrade \& Manuel Bandeira (2000).

Mas é preciso explicitar melhor como proponho fazer a ligação entre cordialidade e correspondência. Vimos que o universo dos grupos modernistas foi fundamental para a consolidação dos projetos que iam se articulando. Portanto, muitas vezes, constituíram-se relações privadas que reverberaram na esfera pública, já que, a partir de contatos pessoais, inclusive pela troca de correspondência informal, circularam problematizações e formas estéticas inovadoras, fossem elas de cunho mais cosmopolita, fossem de cunho mais local ou nacional.

Por sua vez, é sabido que a expressão "cordialidade" se notabilizou como conceito teórico-explicativo(a) do tipo de cultura característico da sociedade brasileira a partir do ensaio de interpretação sociológica Raízes do Brasil (1936), de Sérgio Buarque de Holanda. Mais propriamente, neste livro, o termo "cordial" parte de seu sentido etimológico literal para nomear o "culto da personalidade", o personalismo que extrapola os limites da vida privada e invade o espaço público, obstando a constituição de vínculos ou associações de caráter impessoal. O termo, conforme a acepção buarquiana, faz sobressair a impulsividade, a espontaneidade, a expressão irrefletida diante da alteridade, características que, de algum modo, estariam ainda inscritas num modo de convivência herdado da família patriarcal, tipicamente rural. No trecho a seguir, pode-se ter uma ideia mais precisa do alcance da "cordialidade" tal qual exposto por Sérgio:

Podemos organizar campanhas, formar facções, armar motins, se preciso for, em torno de uma ideia nobre. Ninguém ignora, porém, que o aparente triunfo de um princípio jamais significou no Brasil - como no resto da América Latina - mais do que o triunfo de um personalismo sobre outro. (HOLANDA, 1975, p.138)

Essa cordialidade tão brasileira, segundo o autor, não é nada elogiosa, mas expressão que traduz a consciência acerca de um modo enviesado e excessivamente personalista de gerir as relações no Brasil, que passa ao largo dos princípios democráticos racionais e do pensamento liberal. Tratar-se-ia de uma espontaneidade, antes rica, que, convertida perigosamente em fórmula, poderia ser usada para o bem e para o mal. Como resultado, por exemplo, poderia haver modos e mais modos de se burlar a lei, sem que houvesse uma reprovação cabal desses procedimentos. Pode-se acrescentar que, em termos de uma linguagem fraudulenta e explicitamente ideológica 
- em linha de exercício de crítica da ideologia que se tornou uma corrente de debate a partir dos anos 1960, principalmente -, a escrita pode ser cordial. Porém, no contexto das cartas de que trato, gostaria de recuar um pouco mais, procurando uma espécie de protoforma dessa consciência social da escrita, que se liga mais à interpretação que Freyre empresta ao termo. ${ }^{10}$

É possível que a cordialidade epistolográfica, no limiar do Modernismo e congregando personalidades como Gilberto Freyre e Manuel Bandeira, bem como modernistas de outras paragens, seja um dos últimos momentos que se ligam ao emprego, sem pressupor qualquer artifício, de palavras como "autenticidade" e "província". Inclusive, palavras como "província" são muitas vezes referidas em cartas dos recifenses, cujo emprego se situaria no terreno movediço entre literatura e arte, estética e vida - "Na província, a nostalgia do grande mundo não me deixará de todo; as memórias, que estavam secando, abriram-se de novo em verdadeiras feridas. Meu caro Flag, desculpe tanta literatura; não é só literatura" (Carta de Gilberto Freyre a Manuel Bandeira, com datação "Stanford, 9 de junho de 1931"). Sobre a relação mais estreita entre cartas e Modernismo, afirma Júlio Castañon:

\begin{abstract}
As modificações estéticas trazidas pelo modernismo têm como suas principais características a liberdade em relação aos moldes até então vigentes, a liberdade de pesquisa, a liberdade de criação, com a busca de elementos nacionais, e assim por diante. Também a correspondência refletirá esses aspectos, não apenas em termos de que tratará deles, mas em sua própria formulação. A carta perde a formalidade que se encontra até essa época; torna-se efetivamente troca de ideias, informações, como substituto efetivo da conversa. Sem dúvida, esta modificação propicia um maior desembaraço, de modo que, para além de questões literárias, a carta será também espaço de manifestações pessoais, de informações privadas de pessoas envolvidas na vida literária. (GUIMARÃES, 2004, p.24).
\end{abstract}

A íntima relação entre conversa e carta, mediada pela escrita, evoca a figura do homem cordial, excelente conversador. Aliás, a epistolografia deu origem ao conceito de "homem cordial". Cabe lembrar que, em carta do poeta e diplomata Ribeiro Couto, amigo de Bandeira e de Freyre, ao escritor e diplomata mexicano Alfonso Reyes, o "homem cordial" surge de modo inaugural:

É da fusão do homem ibérico com a terra nova e as raças primitivas que deve sair o "sentido americano" (latino), a raça nova produto de uma cultura e de uma intuição virgem - O Homem Cordial. [...] (Atitude oposta do europeu: a suspicácia e o egoísmo do lar fechado a quem passa) [...] somos qualquer coisa de muito diferente pelo espírito e pelo senso de vida cotidiana. Somos povos que gostam de conversar, de fumar parados, de ouvir viola, de contar modinhas, de amar como puder, de convidar o estrangeiro para tomar café, de exclamar para o luar em noites claras, à janela: - Mas que luar magnífico! Essa atitude de disponibilidade sentimental é toda nossa, é ibero-americana [...]. (Carta de 7 de março de 1931 apud BEZERRA, 2005, p.125-126).

\footnotetext{
${ }^{10}$ Vários estudiosos já se debruçaram sobre as especificidades do conceito no encalço de Sérgio Buarque. Castro Rocha, por sua vez, discutiu os inúmeros mal-entendidos que se seguiram com a popularização do mesmo: "Entretanto, como já mencionei, produziu-se uma particular miscigenação hermenêutica, segundo a qual atribui-se a conceituação a Sérgio Buarque, mas se interpreta o conceito com base em Gilberto Freyre." (ROCHA, 2003, p.210; Cf. também ROCHA, 2004; ROCHA, 1998).
} 
Parece haver uma sutil relação entre o "homem cordial" abordado por Sérgio Buarque e por Ribeiro Couto, na medida em que ambos creditam às nossas raízes ibérica a fácil expressão dos sentimentos, como um "predicado constitutivo" do povo latino-americano, sendo que o grande diferencial do autor de Raízes do Brasil talvez esteja no fato de que busca um rigor teórico e explicativo ausente em seus contemporâneos, abstraindo o sentido "cordial" para compreender, além dos aspectos culturais, os institucionais, cuja manifestação seria patente nas práticas do Estado patrimonial brasileiro. Porém, a despretensão da abordagem de Ribeiro Couto parece se ligar mais à leveza e à positividade que Gilberto Freyre empresta ao termo, na trilha de uma interpretação fundamentalmente culturalista. Assim, a espontaneidade das amizades imediatas, da abertura para as relações pessoais, que remeteria à raiz etimológica de origem latina cordialis - "relativo ao coração" (cf. HOUAISS, 2001) -, liga-se sobretudo ao próprio Freyre, na medida em que este não enxerga um personalismo atávico, uma singularidade que obsta a modernização. ${ }^{11}$ Quando Freyre fala da plasticidade do elemento mestiço como fundamento da nacionalidade, não ressalta outra coisa senão o modo de ser cordial, mediador e articulador de duplos contrastantes, que tem origem no universo da família patriarcal. E, como afirma João Cezar de Castro Rocha, também implica uma "técnica da bondade". Assim, "mestiçagem would have done this in relation to the birth of the Brazilian people, while cordiality would have in regards to the establishment of Brazilian sociability" (ROCHA, 2000, p.79). Talvez a diferença maior para o recifense, com relação a Ribeiro Couto, esteja na importância que dá à presença da herança africana na composição do povo brasileiro. Assim, ambos os conceitos, "mestiçagem" (desenvolvido em Casa-grande \& senzala) e "cordialidade" (apresentado em Sobrados e mucambos), parecem amalgamar-se. A seguir, transcrevo parágrafo do capítulo "Ascensão do bacharel e do mulato" para acompanharmos melhor a argumentação de Gilberto Freyre:

A simpatia à brasileira - o homem simpático de que tanto se fala entre nós, o homem "feio, sim, mas simpático" e até "ruim ou safado, é verdade, mas muito simpático"; o "homem cordial" a que se referem os Srs. Ribeiro Couto e Sérgio Buarque de Holanda - essa simpatia e essa cordialidade, transbordam principalmente do mulato. Não tanto do retraído e pálido como do cor-de-rosa, do marrom, do alaranjado. Ninguém como eles é tão amável; nem tem um riso tão bom; uma maneira mais cordial de oferecer ao estranho a clássica xicrinha de café; a casa; os préstimos. Nem modo mais carinhoso de abraçar e de transformar esse rito como já dissemos orientalmente apolíneo de amizade entre homens em expansão caracteristicamente brasileira, dionisiacamente mulata, da cordialidade. 0 próprio conde de Gobineau que todo o tempo se sentiu contrafeito ou mal entre os súditos de Pedro II, vendo em todos uns decadentes por efeito da miscigenação, reconheceu, no brasileiro, o supremo homem cordial: "très poli, très accueillant, très aimable". Evidentemente, o brasileiro que tem sua pinta de sangue africano ou

11 A propósito, João Cezar de Castro Rocha afirma que, nas sucessivas edições de Raízes do Brasil: "De um lado, o autor acrescentou notas, com o objetivo de enriquecer os argumentos com dados. Tratava-se do historiador relendo o ensaio de estreia. De outro, Sérgio Buarque alterou ou simplesmente eliminou passagens nas quais celebrava o trabalho de Gilberto Freyre. Tratava-se do intelectual defendendo sua concepção. Numa leitura menos cautelosa, o teórico da cordialidade pagava tributo à própria criação, revelando um Sérgio Buarque cordial, à revelia do lúcido autor de Raízes do Brasil. E aqui vale lembrar que, apesar de terem sido introduzidos acréscimos e mudanças importantes em edições posteriores de Sobrados e mucambos, Freyre manteve integralmente as menções ao trabalho de Sérgio Buarque, tal como constavam em 1936." (ROCHA, 2004, p.67). 
alguma coisa de africano na formação de sua pessoa; não o branco ou o "europeu" puro, às vezes cheio de reservas; nem o caboclo, de ordinário desconfiado e que ri pouco. (FREYRE, 2003, p.791)

A simpatia do brasileiro, chamada de cordialidade por Freyre, teria possibilitado a ascensão do mulato numa sociedade extremamente desigual. Foi também por uma questão de sobrevivência que se misturou. Tratava-se, pois, de uma adaptação plástica às novas condições impostas pela sociedade livre. O riso, o uso de diminutivo, os índices de familiarização com as pessoas e tantas outras manifestações de aproximação são fórmulas usadas por esse homem cordial, que muitas vezes espera algo em contrapartida, ou uma retribuição por sua lealdade aparentemente desinteressada. Generalizando, o lado socialmente devastador das relações personalistas, se podemos acompanhar os argumentos de autores como Roberto Schwarz e Maria Sylvia de Carvalho Franco, estaria no encobrimento do arbítrio, do mandonismo, do mecanismo social eivado de desfaçatez, das hierarquias sociais, por assim dizer, deletérias, da docilidade que acoberta a violência, algo também apontado por Freyre: "Não há brasileiro de classe mais elevada, mesmo nascido e criado depois de oficialmente abolida a escravidão, que não se sinta aparentado do menino Brás Cubas na malvadeza e no gosto de judiar com negro" (FREYRE, 1999, p.370). Obviamente as sutilezas dos argumentos são muitas, mas valeria a pena citar palavras que recuperam pressuposto semelhante, qual seja, a presença de uma espécie de técnica tipicamente brasileira, expressa pelo favor, pela capacidade de articulação e de concertação. Para Schwarz: "Assim, com mil formas e nomes, o favor atravessou e afetou no conjunto a existência nacional, ressalvada sempre a relação produtiva de base, esta assegurada pela força." (SCHWARZ, 1988, p.16). Mais adiante: "O favor é nossa mediação quase universal - [...] é compreensível que os escritores tenham baseado nele a sua interpretação do Brasil, involuntariamente disfarçando a violência, que sempre reinou na esfera da produção" (SCHWARZ, 1988, p.16). Para Maria Sylvia, em seu estudo sobre a prática do coronelismo:

\begin{abstract}
Essa dominação implantada por meio da lealdade, do respeito e da veneração estiola no dependente até mesmo a consciência de suas condições mais imediatas de existência social, visto que suas relações com o senhor apresentam-se como um consenso e uma complementariedade, em que a proteção natural do mais forte tem como retribuição honrosa o serviço, e resulta na aceitação voluntária de uma autoridade que, consensualmente, é exercida para o bem. Em suma as relações entre senhor e dependente aparecem como inclinação de vontades do mesmo tipo, como harmonia, e não como imposição da vontade do mais forte sobre o mais fraco, como luta. (FRANCO, 1997, p.94).
\end{abstract}

Embora sejam muitos os caminhos e atalhos da cordialidade e seu "parente próximo", o favor, pode-se afirmar que o conceito acadêmico tem sido indiscriminadamente utilizado, tanto por leigos quanto por intelectuais, às vezes sem se apontar para o núcleo palpável de sua significação e sempre relacionando-o a Raízes do Brasil. ${ }^{12}$ Mas essa ambiguidade e fluidez está inscrita em sua própria origem

\footnotetext{
12 Afirmou João César de Castro Rocha: "Apesar dessas diferenças, uma leitura muito particular
} tem predominado. O conceito de cordialidade é atribuído somente ao trabalho de Sérgio 
plástica e ensaística, o que demonstra que a expressão ainda pode ser produtiva, principalmente se articulada com a produção literária e intelectual dos anos 1920 e 1930, quando ainda não havia uma tradição acadêmica no país, o que só começaria a acontecer após a década de 1940. Porém, vale ainda dizer, a consolidação da academia não impede que personagens que retomam o trickster se reatualizem de modo a significar uma disposição tipicamente brasileira. Como exemplo, veja-se o malandro de Antonio Candido, abstraído em "Dialética da malandragem", sua célebre leitura do livro Memórias de um sargento de milícias, de Manoel Antônio de Almeida, publicada em 1970 :

Na sua estrutura mais íntima e na sua visão latente das coisas, esse livro exprime a vasta acomodação geral que dissolve os extremos, tira o significado da lei e da ordem, manifesta a penetração recíproca de grupos, das ideias, das atitudes mais díspares, criando uma espécie de terra-de-ninguém moral, onde a transgressão é apenas um matiz na gama que vem da norma e vai ao crime. (CANDIDO, 2004, p.44).

A malemolência malandra, também na visão de Antonio Candido, subverte, "amaina as quinas", mas encobre a violência inscrita no processo histórico pautado pela exclusão. Essas tensões que buscam traduzir uma dinâmica tipicamente brasileira ganharão diversos matizes e acordes no ensaísmo brasileiro ao longo dos anos. Até por isso considero ser fundamental revisitar a ideia mais elementar da cordialidade, para observar os sentidos díspares que subentende, aos quais outras camadas seriam acrescentadas. Quando procuro observar a cordialidade na correspondência, é sobretudo em busca do diálogo com textos produzidos no calor da hora, em um período que sentia os efeitos de uma urbanização acelerada a se chocar com a herança rural e escravocrata, lutando contra a herança colonial.

A ambiguidade conceitual implicada na palavra, consequência histórica da grande produtividade que teve ao longo do século $X X$, confirma que não se pode chegar a palavras categóricas ou a conceitos absolutos. O termo, em seu sentido inaugural, quando a excessiva autoconsciência ainda não teria matado definitivamente a possibilidade de uma cordialidade espontânea, sobrevive. Desse modo, seu emprego também pode permitir compreender os gestos sutis da dinâmica da sociabilidade entre escritores, artistas e intelectuais, em uma época de parca diferenciação social. Vejase, nesse sentido, uma autodefinição de José Olympio (1902-1990) - maior editor de Gilberto Freyre e primeiro editor de Raízes do Brasil - para se notar sua produtividade. À pergunta de Elias Fajardo da Fonseca sobre "De onde vem esse carinho que comovia os escritores todos", J.O. prontamente responde, em 1984:

Cada um nasce como é. Nasci para ser cordial, nunca fui bajulador. Nunca chamei presidente da República de Excelência; almocei ao lado direito do Café Filho, almocei com Nereu Ramos, com Ademar de Barros. Só não almocei com Getúlio. (In: PEREIRA, 2008, p.401).

Buarque, como se, no mesmo ano de 1936, Gilberto Freyre não tivesse proposto uma concepção alternativa, aliás, muito mais próxima à definição de Ribeiro Couto. [...] Ora, a concepção de Freyre tem muito mais afinidade com certa imagem da cultura brasileira, cuja pretensa vocação seria mediar conflitos, em lugar de explicitá-los." (ROCHA, 2003, p.215). 
É curioso também que, apesar de no meio acadêmico o termo denotar algo carregado de desprestígio, na medida que se liga a inúmeros fatores que deveriam ser "superados" para que o Brasil, de fato, se modernizasse, talvez seja em política externa que seus semas mais elementares sobrevivam como fator produtivo, sobretudo quando se remete aos recursos do soft power, de habilidade em concertação política e cooperação. Por certo, esses recursos brasileiros inovadores no cenário internacional deveriam se combinar a índices de qualidade de vida convincentes no plano interno, em especial no que diz respeito à pobreza, à educação e à violência, avançando propostas sociais convincentes, para além de uma dinâmica conservadora. ${ }^{13}$ De qualquer modo, é interessante notar que a produtividade do termo é patente e, ainda mais, desde o início de sua popularização, esteve ligado a uma maneira vital de se traduzirem laços - mais ou menos problemáticos - constituídos desde a vida prática, a espraiar-se pela formas simbólicas.

\section{Cordialidade e modernismo}

A cordialidade espontânea e as relações benfazejas, mesmo que misturadas com momentos de estranhamento interpessoais, teriam garantido ao brasileiro, para falar com Freyre, relacionar-se com a alteridade - a mulata, o mestiço, a feijoada, o samba, a boêmia, a cachaça, o futebol, o candomblé etc. -, produzindo configurações estéticas e culturais renovadas, marcadas pela singular presença do elemento popular. Conteria, portanto, uma semântica de aproximação, um procedimento relacional característico.

Nesse contexto, a oralidade foi marca decisiva nos escritos dessa geração, como podemos observar no conjunto da correspondência trocada entre Gilberto Freyre e Manuel Bandeira. Na carta com datação "Rio de Janeiro, 4 de junho [de 1927]", é possível notar a descontração e o à-vontade com a temática mundana na correspondência entre os amigos:

[...] Se se foder, passa copo de corno adiante. Quando sai a figura correspondente ao cavalinho de outro parceiro, empurra-se o cavalinho do outro parceiro e passase o copo adiante. [...] / O joguinho é muito excitante e quando menos se espera está tudo no porre. / Teu poema, Gilberto, será a minha eterna dor de corno. Não posso me conformar com aquela galinhagem tão gozada, tão sem vergonhamente lírica, trescalando a baunilha de mulata asseada. Sacana!". ${ }^{14}$

Uma hipótese, que aqui apresentamos, é de que a sociabilidade tipicamente brasileira deixou marcas também na escrita modernista. Mas não só: a conjunção de

${ }^{13}$ Cf. conceitos fundamentais de política externa em: CERVO, 2008; VIDIGAL, 2010.

14 A proposta de edição de referida carta, de número 2 no conjunto da Correspondência organizada em tese de doutorado (VICENTE, 2008), apresenta a seguinte nota de edição: "Classificação original do documento (FGF): doc 1a. Carta. Manuscrito autógrafo com caneta tinteiro preta. Datação: 'Rio, 4 de junho'. Papel amarelado, de gramatura alta. Seis folhas, sete páginas manuscritas, sendo a primeira folha manuscrita frente e verso e o restante somente frente. No alto, encontra-se a seguinte paginação: '-' (primeira folha); ' 2 ' (segunda folha); ' 3 ' (terceira folha); ' 3 bis' (quarta folha); ' 4 ' (quinta folha); ' 5 ' (sexta folha). Dimensões: 29,9 x 11 $\mathrm{cm}$. Documento em boas condições. Acompanha gravuras". 
pessoas em grupos, os contatos e as trocas que viabilizaram o Modernismo como movimento foram sobremaneira facilitados pela correspondência. Gostaria, portanto, de ressaltar a importância da troca entre pessoas no meio intelectual e cultural e também o sentido das escritas que elas enformam. Quando Bandeira se refere a Freyre confessando sua completa admiração pelo poema - ao que tudo indica, "Bahia de Todos os Santos e de Quase Todos os Pecados", escrito em época na qual o sociólogo parecia indeciso entre a literatura e a ciência -, afirma a embriaguez da experiência por meio de palavras informais, que se remetem ao universo da boêmia e de aventuras sexuais. Tabus também estão sendo discretamente superados. $O$ àvontade da carta é, portanto, contíguo à atmosfera do poema de Gilberto Freyre, que procura construir uma espécie de correlativo objetivo, utilizando expressão de T. S. Eliot, da cidade baiana, abordando-a a partir de um erotismo como que descarado, sem rodeios:

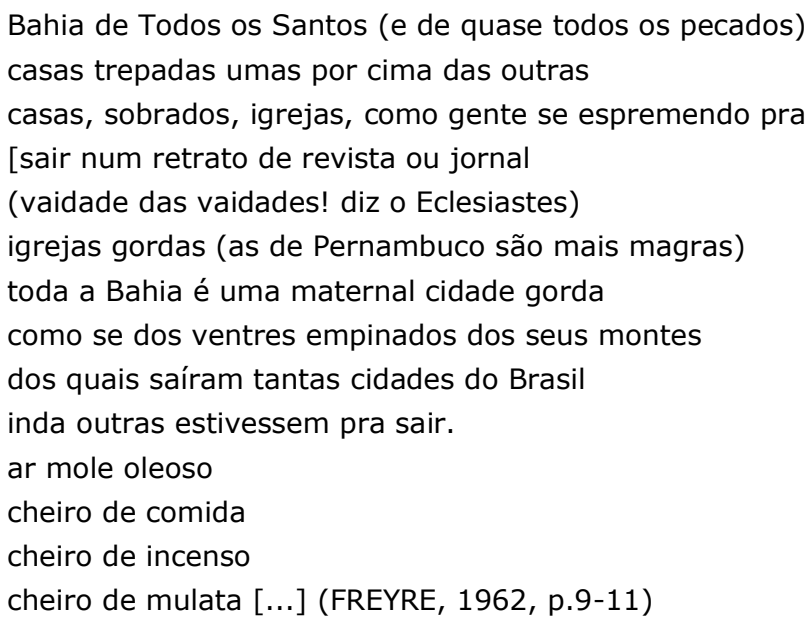

Desse modo, com relação às trocas que viabilizam a questão do trabalho artístico e intelectual, à aparência livre e despretensiosa, à oralidade da Correspondência de Gilberto Freyre e Manuel Bandeira - perspectiva que ainda reforça a produtividade de inserirmos os termos no circuito e no tempo de sua gestação -, podemos afirmar que estamos diante de uma epistolografia cordial. A liberdade com que os assuntos se desenrolam nas mãos dos remetentes também permite, além da questão propriamente formal, fazer considerações várias sobre a vida dos atores envolvidos nas "narrativas" epistolares. Também, a própria vida social, inclusive com suas mazelas, se abre para a análise.

Restaria, por fim, constatada a produtividade estética da cordialidade a partir de sua componente relacional e informal, indagar sobre as consequências políticas da realidade que a mesma ajuda a produzir. Nesse sentido, remeto às palavras de Lilia Schwarcz em parágrafo que encerra o artigo "Complexo de Zé Carioca. Notas sobre uma identidade mestiça e malandra": "O objetivo não é elogiar, qualificar ou tornar rígida e oficial uma determinada representação, mas antes distinguir certas continuidades que fazem da nossa interpretação uma leitura singular e cultural." (1994, p.31-2). 
Gostaríamos de especular também como permanências tais como a cordialidade poderiam implicar uma compreensão, ainda hoje, problemática acerca da inter-relação entre espaços públicos e privados. Além disso, partindo de uma leitura não monumentalizadora da escrita dessa geração - tendo por base textos inéditos e dispersos -, valeria a pena promover uma análise do encaminhamento político centralizador e agregador do Estado que começa a se desenhar, sobretudo após a Revolução de 1930. Com os tempos em ritmo acelerado de reconfiguração política em moldes republicanos, parecia definir-se, no Brasil do século $\mathrm{XX}$, o traçado de uma democracia peculiar - a conciliar, de modo problemático, desigualdade, modernização seletiva, trânsitos extraordinários e relativa estabilidade de uma próspera e diminuta elite, em contraste com uma imensa massa de excluídos -, o que se reflete, de muitas maneiras, na dinâmica das redes de sociabilidade do período. São desafios prementes do Brasil na primeira metade do século XX que, de muitas maneiras, infelizmente, ainda resistem nas primeiras décadas do século XXI.

\section{REFERÊNCIAS}

Andrade, Mário de; Bandeira, Manuel. Correspondência Mário de Andrade \&

Manuel Bandeira. Organização, prefácio e notas de Marcos Antonio de Moraes. São Paulo: EDUSP, 2000.

ANDRADE, Oswald. Manifesto Antropófago. In: SCHWARTZ, Jorge. Vanguardas latino-americanas: polêmicas, manifestos e textos críticos. São Paulo: Editora da Universidade de São Paulo: Iluminuras: FAPESP, 1995.

Bezerra, Elvia. Ribeiro Couto e o homem cordial. Revista Brasileira, Rio de Janeiro, v. 11, n. 44, p. 123-130, jul./set. 2005.

Bürger, Peter. Teoria da vanguarda. Lisboa: Vega, 1993.

CANDIDO, Antonio. Dialética da malandragem. In: O discurso e a cidade. 3 . ed. Rio de Janeiro: Ouro sobre Azul, 2004. p.17-46.

Formação da literatura brasileira. Belo Horizonte, Rio de Janeiro: Editora Itatiaia Limitada, 1993.

Cardozo, Joaquim. Um poeta pernambucano Manuel Bandeira. In: Freyre, G. et al. Livro do Nordeste. Edição fac-similar à de 1925. Introdução de Mauro Mota e prefácio de Gilberto Freyre. 2.ed. Recife: Arquivo Público Estadual, 1979. p.124-125.

CERVO, Amado Luiz. Inserção internacional: formação dos conceitos brasileiros. São Paulo: Saraiva, 2008.

FONSECA, Elias Fajardo. Entrevista com J. O. In: PEREIRA, José Mario (Org.). José Olympio. O editor e sua Casa. Rio de Janeiro: Sextante, 2008. p.400-3.

FRANCO, Maria Sylvia. Homens livres na ordem escravocrata. 4. ed. São Paulo: Fundação Editora da UNESP, 1997. 
FREYRE, Gilberto. Cartas do próprio punho sobre pessoas e coisas do Brasil e do estrangeiro. Seleção, organização e introdução de Sylvio Rabello. Rio de Janeiro: Conselho Federal de Cultura, 1978.

Casa-grande \& senzala: formação da família brasileira sob o regime da economia patriarcal. São Paulo: Ed. Global, 1999.

Casa-grande \& senzala: formação da família brasileira sob o regime da economia patriarcal. São Paulo: Ed. Global, 2006.

et al. Livro do Nordeste. Introdução de Mauro Mota e prefácio de Gilberto Freyre. 2.ed. Recife: Arquivo Público Estadual, 1979. Edição Comemorativa do primeiro centenário do Diário de Pernambuco. Edição fac-similar ao original de 1925.

Sobrados e mucambos: decadência do patriarcado rural e desenvolvimento do urbano. São Paulo: Global, 2003.

Talvez Poesia. Rio de Janeiro: J. Olympio, 1962.

Guimarães, Júlio Castañon. Contrapontos: notas sobre correspondência no modernismo. Rio de Janeiro: Fundação Casa de Rui Barbosa, 2004.

Gullar, Ferreira. Vanguarda e subdesenvolvimento: ensaios sobre arte. Rio de Janeiro: Civilização Brasileira, 1969.

Holanda, Sérgio Buarque de. Raízes do Brasil. 8. ed. Rio de Janeiro: J. Olympio, 1975.

Houaiss, Antonio; Villar, Mauro de Salles. Dicionário Houaiss da língua portuguesa. Rio de Janeiro: Objetiva, 2001.

MICELI, Sérgio. Nacional estrangeiro: história social e cultural do modernismo artístico em São Paulo. São Paulo: Companhia das Letras, 2003.

PONTES, Heloisa. Destinos mistos: os críticos do Grupo Clima em São Paulo (194068). São Paulo: Companhia das Letras, 1998.

Intérpretes da metrópole: história social e relações de gênero no teatro e no campo intelectual, 1940-1968. São Paulo: Editora da Universidade de São Paulo; FAPESP, 2010.

ROCHA, João Cezar de Castro. As raízes e os equívocos da cordialidade brasileira. In: NENHUM Brasil existe. Pequena Enciclopédia. Org. João C. C. Rocha. Rio de Janeiro: UERJ: Topbooks: UniverCidade, 2003.

Rocha, João Cezar de Castro. Literatura e cordialidade: o público e o privado na cultura brasileira. Rio de Janeiro: EdUERJ, 1998.

O exílio do homem cordial. Rio de Janeiro: Ed. Museu da República, 2004. The origins and errors of Brazilian cordiality. Portuguese Literary \& Cultural Studies, Dartmouth, n.4/5, p.73-85, Spring/Fall 2001.

SAID, Edward. Humanismo e crítica democrática. Trad. de Rosaura Eichenberg. São Paulo: Companhia das Letras, 2007. 
SCHWARCZ, Lilia. Complexo de Zé Carioca: sobre uma certa ordem da mestiçagem e da malandragem. In: XVIII Encontro Anual da ANPOCS, Caxambu/MG, 23-27 nov. 1994.

SCHWARZ, Roberto. As ideias fora do lugar. In: Ao vencedor as batatas.

São Paulo: Livraria Duas Cidades, 1988. p.13-25.

SOUZA, Jessé. A modernização seletiva: uma reinterpretação do dilema brasileiro. Brasília: Editora Universidade de Brasília, 2000.

SÜSSEKIND, Flora. Cinematógrafo de letras: literatura, técnica e modernização no Brasil. São Paulo: Companhia das Letras, 1987.

VICENTE, Silvana Moreli. Cartas provincianas: correspondência entre Gilberto Freyre e Manuel Bandeira. São Paulo: Faculdade de Filosofia, Letras e Ciências Humanas da Universidade de São Paulo, 2008.

VIDIGAL, Carlos. Brasil: potência cordial? A diplomacia brasileira no início do século XXI. RECIIS, Rio de Janeiro, v.4, n.1, p.36-45, mar.2010.

Title: Nuances of the cordiality: the correspondence of writers and inflexions of the debates in the Brazilian Modernism

Abstract: This article intends to discuss the possibility of reading the Gilberto Freyre and Manuel Bandeira's unpublished letters taking the concept of "cordiality" as basis, as the essayist presents it in his book Sobrados e mucambos (1936). Cordiality and epistolography can be connected in so far as they reinforce the approximation between contrasting elements, by employing a relational and informal language, linked to the everyday life. This articulation will be assimilated as an important item on the modernist agenda, mainly after the final year of the 1920s. Thus, one will reflect on a cordial predisposition in the Brazilian Modernism and on its likely literary incorporation by looking for subtle information presented in the epistolar form and in some documents of the author's archives.

Keywords: Gilberto Freyre. Manuel Bandeira. Correspondence. Modernism. Epistolography.

Recebido em: 29/05/2013. Aceito em 30/11/2013 